\title{
FABRICATION, EVALUATION OF DRUG LOADING CAPABILITY AND CHARACTERIZATION OF 3D-NANO-CELLULOSE NETWORK MATERIALS PRODUCED BY BACTERIA OF FERMENTED AQUEOUS GREEN TEA EXTRACTIN SELECTED CULTURE MEDIA
}

\author{
THANH XUAN NGUYEN ${ }^{*}$, NGAN PHUC HOANG ${ }^{2}$, CUONG B. A. CAO ${ }^{1}$
}

${ }^{1}$ Institute of Scientific Research and Applications, Hanoi Pedagogical University 2, ${ }^{2}$ Hoa Lu University; Vietnam

Email: nguyenxuanthanh@hpu2.edu.vn

Received: 04 Oct 2019, Revised and Accepted: 14 Nov 2019

ABSTRACT

Objective: The study aims for the fabrication, evaluation of drug loading capability and characterization of 3D-nano-cellulose network materials produced by bacteria of fermented aqueous green tea extract in selected culture media.

Methods: 3D-nano-cellulose network (3DNC) materials can be produced by bacteria living in a fermented aqueous green tea extract. 3DNCs include nano-fibers forming networks, which are capable of drug loading to form a prolonged release therapy to improve drug bioavailability. In this study, 3DNC materials are biosynthesized by aerobic bacteria in the standard medium (SM), coconut water (CW) and rice water (RW). 3DNCs were prepared and evaluated for drug carrier using famotidine as a model drug. Famotidine was loaded in 3DNC by the absorption method. 3DNCs were characterized by using FE-SEM and FTIR spectroscopy.

Results: The 3DNCs obtained from CW, and RW have the same characteristics as the 3DNC obtained from the SM, and 3DNCs can be fabricated with the desired thickness and diameter in all three types of culture media. 3DNCs absorbed famotidine in optimum condition without any difference in famotidine loading $(28.2 \mathrm{mg}$ ) and famotidine entrapment efficiency $(90 \%)$. Investigation of the 3DNC structure using FE-SEM has shown that the cellulose fibers of 3DNC-SM and 3DNC-CW have a stable structure without structural change when loading drug under optimal condition.

Conclusion: The results indicate the potential for using 3DNC-SM and 3DNC-CW to design the drug delivery system.

Keywords: Drug delivery, Drug loading, Famotidine, Fermented aqueous green tea extract, 3D-nano-cellulose network

(C) 2020 The Authors. Published by Innovare Academic Sciences Pvt Ltd. This is an open access article under the CC BY license (http://creativecommons.org/licenses/by/4.0/) DOI: http://dx.doi.org/10.22159/ijap.2020v12i1.35969 Journal homepage: https://innovareacademics.in/journals/index.php/ijap

\section{INTRODUCTION}

Green tea (Camellia sinensis) is one of the most widely consumed beverages around the world. Its antioxidant activity and other health benefits have gained considerable notoriety in recent years. The fermented aqueous green tea extract contains bacteria producing 3DNC. The metabolites of bacteria during the fermentation include 3DNC. The 3DNC has the structure of super-thin nano-fibers with great tensile and mechanical strength. It is proved that the 3DNC exposes the potential of being a delivery system with its properties. The use of 3DNC of coconut jelly (made from coconut juice after the fermentation of bacteria Acetobacter xylinum) in the coating for Paracetamol by spraying technique was reported [1]. Their results indicated that the 3DNC membranes were able to increase releasing time of the drug and improve the efficiency of drug users. 3DNC membrane from the fermentation of Gluconacetobacter xylinum in the standard medium (Hestrin-Schramm) for transporting and releasing berberine in vitro was tested [2]. The study controlled drug releasing of 3DNC in artificial models including stomach and intestine. The gained information shows that berberine released with a low rate in acidic condition, but the normal rate in alkaline condition and high releasing rate in neutral $\mathrm{pH}$ condition. Famotidine, a gastrointestinal drug, is soluble in acid and weak solubility in water [3]. Its activity reduces gastric secretion by inhibiting the interaction between histamine and $\mathrm{H}_{2}$ receptor in the gastric mucosa wall and decreases the secretion of $\mathrm{HCl}$ in gastric juice. Therefore, famotidine is utilized to cure gastric ulcers. However, the low bioavailability of famotidine (about $40-45 \%$ ) has hindered its use in therapeutic applications [3], especially, in oral treatment, which is a conventional way to deliver drug with reduced costs and less pressure on patients [4]. Therefore, a system that helps drugs to be enhanced aqueous solubility is required to increase the bioavailability of the drug. A novel amino acid prodrug of famotidine with better solubility and bioavailability was synthesized and characterized [5]. The floating pulsatile concept was applied to increase the gastric residence in the dosage form having lag phase followed by a burst release. The recent research indicated that famotidine could be successfully delivered to provide night-time relief of gastric acidity by formulating floating pulsatile drug delivery system [6]. It is demonstrated that the multipleunit floating-bio-adhesive cooperative mini tablets enhanced the oral bioavailability of famotidine in rats [3]. The study also proved that the multiple-unit floating-bio-adhesive cooperative mini-tablets might/could be a promising gastro-retentive delivery system for stomach therapeutic drugs. The acid function of carboxymethyl-beta-cyclodextrin in the enhancement of the chemical stability, oral-route bio-availability and bitter taste of famotidine were evaluated [7]. The rate of release of famotidine through the construction of liquid, solid tablets in both in vitro and in vivo were shown [8]. The pharmacokinetics and bioavailability of famotidine on ten Chinese volunteers were studied [9]. Our research aims to fabricate and evaluate the properties as drug carriers of the 3DNCs produced by Acetobacter bacteria from fermented aqueous green tea extract in selected culture media.

\section{MATERIALS AND METHODS}

\section{Materials}

Acetobacter bacteria producing cellulose from fermented aqueous green tea extract $[10,11]$ were cultured in the clean laboratory of Microorganism-Animal, Institute of Scientific Research and Applications (ISA)-Hanoi Pedagogical University 2 (HPU2).

Famotidine $99.5 \%$ (Sigma-USA), tablets Famotidine (FAMSYN-20, Haryana-India), dialysis bag (MWCO: 12 000-14 000; ServaGermany), yeast extracts (USA), peptone (European Union), and other standard chemicals were used in the analysis.

Field emission scanning electron microscopes (FE-SEM, Hitachi, Japan), Fourier transform infrared spectrophotometer (FTIR, Shimadzu, Japan), Spectrophotometers UV-Vis 2450 (Shimadzu, Japan), analytic scale (Sartorius, Switzerland); magnetic stirrer (IKA, Germany), low speed rotator (Orbital Shaker gallenkamp, England), shaker (Lab companion, SKF-2075, Korea), oven and incubator (Binder, Germany), antiseptic cabin (Haraeus), and antiseptic autoclave (HV-110/HIRAIAMA, Japan) were used. 
Methods

Preparation of Acetobacter bacteria from fermented aqueous green tea extract

The green tea leaves ( $20 \mathrm{~g}$ ) were added to $1000 \mathrm{ml}$ of boiled water and allowed to infuse for 10-15 min. The infusion was filtered to remove the tea leaves. Sugar (100 g) was dissolved in hot aqueous green tea extract, and preparation was left to cool to room temperature. The aqueous green tea extract was then poured into sterile glass bottles. The bottles were then covered with sterile muslin cloths and incubated at $30{ }^{\circ} \mathrm{C}$. The fermentation could be carried out to produce the 3DNC $[10,11]$. The trapping process of Acetobacter bacteria from fermented aqueous green tea extract was described in fig. 1 [11].

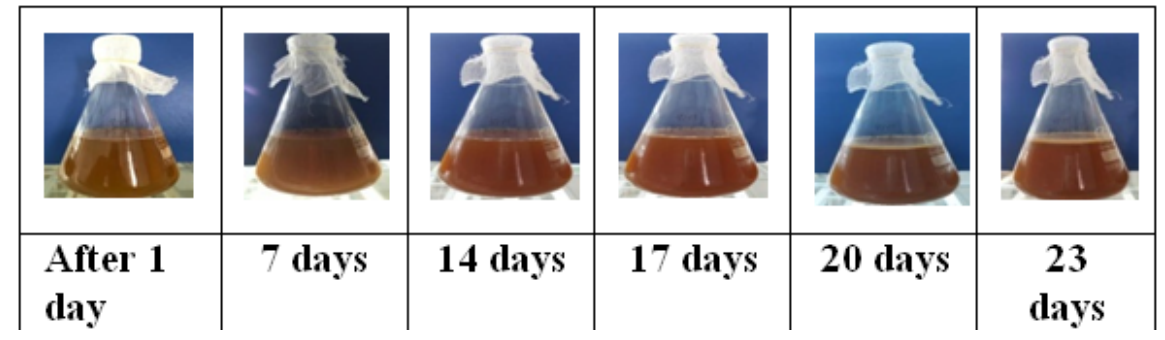

Fig. 1: Trapping Acetobacter bacteria from fermented aqueous green tea extract

After receiving the Acetobacter bacteria from the fermented aqueous green tea extract [11], Acetobacter bacteria were cultured in selected nutrient media (SM, CW, RW) to produce the 3DNCs.

\section{Fabrication and characterization of 3D-nano-cellulose network material (3DNC)}

Acetobacter bacteria fermented in three selected culture media

Firstly, glucose (20 g), peptone (5 g), diammonium phosphate (2.7 g), yeast extracts $(5 \mathrm{~g})$, citric acid $(1.15 \mathrm{~g})$ and double-distilled water $(1000 \mathrm{ml})$ were used in SM $[12,14]$. Secondly, glucose $(20 \mathrm{~g})$, peptone $(10 \mathrm{~g})$, diammonium phosphate $(0.5 \mathrm{~g})$, ammonium sulfate $(0.5 \mathrm{~g})$ and coconut water $(1000 \mathrm{ml})$ were used in CW $[13,14]$. Thirdly, glucose $(20 \mathrm{~g})$, peptone $(10 \mathrm{~g})$, diammonium phosphate $(0.5 \mathrm{~g})$, ammonia sulfate $(0.5 \mathrm{~g})$ and rice water $(1000 \mathrm{ml})$ were used in RW [14].

\section{Treatment of the 3DNCs before drug absorption}

The 3DNCs obtained from culture media were treated with $0.3 \mathrm{M}$ $\mathrm{NaOH}$ solution in an autoclave at $113{ }^{\circ} \mathrm{C}$ for $15 \mathrm{~min}$ to remove bacterial cells, debris and other culture medium impurities. The 3DNCs were thoroughly rinsed with distilled water until reaching neutral $\mathrm{pH}$ and stored at $4{ }^{\circ} \mathrm{C}$ for further use $[13,15,16]$.

\section{Evaluation of the purity of the 3DNC}

The present of D-glucose in the 3DNC was determined by Fehling reagent. If there is a D-glucose present in the 3DNC, the Fehling reagent will give a reddish precipitate $[17,18]$. The presence of protein in 3DNC was determined by the precipitation reaction with trichlor-acetic acid $[17,18]$.

\section{Determination of the amount of the formed 3DNC}

The purified 3DNC was dried at $105{ }^{\circ} \mathrm{C}$ until reaching a constant mass $[13,15,16]$.

\section{Determination of the structure of the 3DNC}

The samples were heated at $40{ }^{\circ} \mathrm{C}$ in 20 min, covered, then a thin platinum layer and samples were put into the sample chamber. The field emission scanning electron microscopes (FE-SEM, Hitachi S-4800 with magnification $M=20-800000$, resolution $\delta=1.0 \mathrm{~nm}$, piezoelectric accelerator $\mathrm{U}=10 \mathrm{kV}$ ) was used for examination of the samples.

\section{Determination of the interaction of the 3DNC to the drug}

The samples were directly measured by reflectometry method in $20{ }^{\circ} \mathrm{C}$, moisture $40-43 \%$. The FTIR was used for examination of the samples.

\section{Evaluation of drug loading and entrapment efficiency of 3DNCs}

Famotidine was loaded in 3DNCs by the absorption method [19]. The 3DNCs with a diameter of $1.5 \mathrm{~cm}$ and a thickness of $1 \mathrm{~cm}$ created from culture media (SM, CW, RW) absorbed famotidine in the optimized conditions [14]. The concentration of the famotidine remaining in the loading solution was determined using a UV-Vis spectrophotometer (UV-Vis 2450, Shimadzu, Japan) at $265 \mathrm{~nm} \mathrm{[2,} \mathrm{4,}$ $11,14,19]$. A calibration curve of famotidine solution in $\mathrm{HCl} 0.1 \mathrm{~N}$ within the concentration range of $1 \mu \mathrm{g} / \mathrm{ml}$ to $6 \mu \mathrm{g} / \mathrm{ml}$ was used for determining famotidine loadings in 3DNCs samples.

The amount of loaded famotidine into 3DNC was calculated according to formula 1.

$$
\boldsymbol{m a b}=(\boldsymbol{m} 1-\boldsymbol{m} 2)(1)
$$

Where: $\mathrm{mab}(\mathrm{mg})$ is the amount of famotidine that is loaded into the 3DNC; $\mathrm{m} 1$ is the initial famotidine dose in solution; $\mathrm{m} 2$ is the excessive amount of famotidine existing in the solution after a certain period of time 3DNC absorbs the famotidine.

The famotidine entrapment efficiency (EE) of 3DNCs was calculated according to formula 2 [4]

$$
\boldsymbol{E} \boldsymbol{E}=\frac{\boldsymbol{m a b}}{\boldsymbol{m} \mathbf{1}} \boldsymbol{x} \mathbf{1 0 0} \%(2)
$$

\section{Statistics}

All results are processed by Excel 2010 and it is performed by the mean \pm standard deviation (SD) and two-way ANOVA test. The results are considered to be significant with $\mathrm{p}<0.05$.

\section{RESULTS}

Fabrication and characterization of the 3D-nano-cellulose network material (3DNC)

The 3DNCs with a diameter of $1.5 \mathrm{~cm}$ and a thickness of $1 \mathrm{~cm}$ are produced by Acetobacter bacteria in the culture media (SM, CW, RW) from 7 to $14 \mathrm{~d}[11,20,21]$. According to previous studies, it is possible to create 3DNCs with different shapes and thickness depending on the intended use $[2,14]$. In the present study, the 3DNCs with a thickness of $1 \mathrm{~cm}$ (depending on the time of culture) and a diameter of $1.5 \mathrm{~cm}$ (depending on the size of the culture well) were created for the application via the oral route. The thickness of the 3DNC in different positions was measured by a ruler. The results showed that the thickness and the diameter of the M3NCs produced from the culture media were relatively homologous.

Fehling reagent was used to detect the presence of D-glucose in the 3DNCs. The results showed that there was no reddish brown precipitate. Therefore, the 3DNCs did not contain D-glucose. The protein in the 3DNCs was determined by the reaction of protein precipitate with trichlor-acetic acid. The result indicated that the presence of protein was not detected in the 3DNCs.

To determine the amount of forming 3DNC, the purified 3DNCs were dried at $105{ }^{\circ} \mathrm{C}$ until reaching a constant mass. The result showed that the dried mass of the 3DNC created in SM was the highest. 
A field emission scanning electron microscope (FE-SEM, Hitachi, Japan) was used to visualize the surface morphology of the samples. SEM images of the 3DNCs (SM, CW, RW) before and after loading famotidine were shown in fig. 2. As a result, 3DNCs

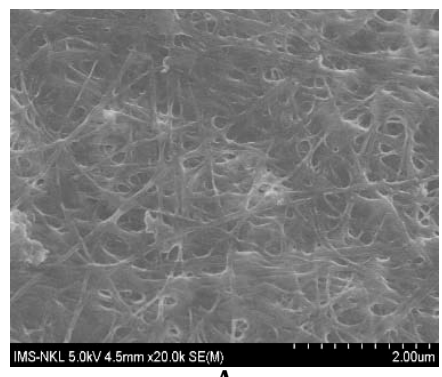

A
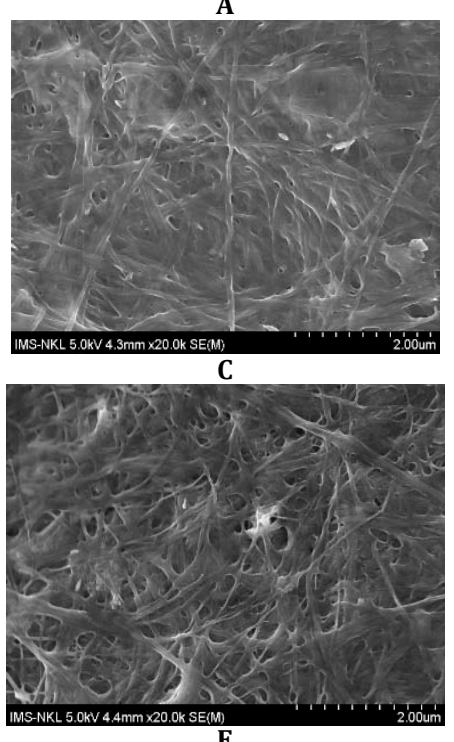

E have the homogeneous fiber structure networks without significant changes in the structure before and after loading famotidine. These results are very similar to those of our previous study $[11,20]$.
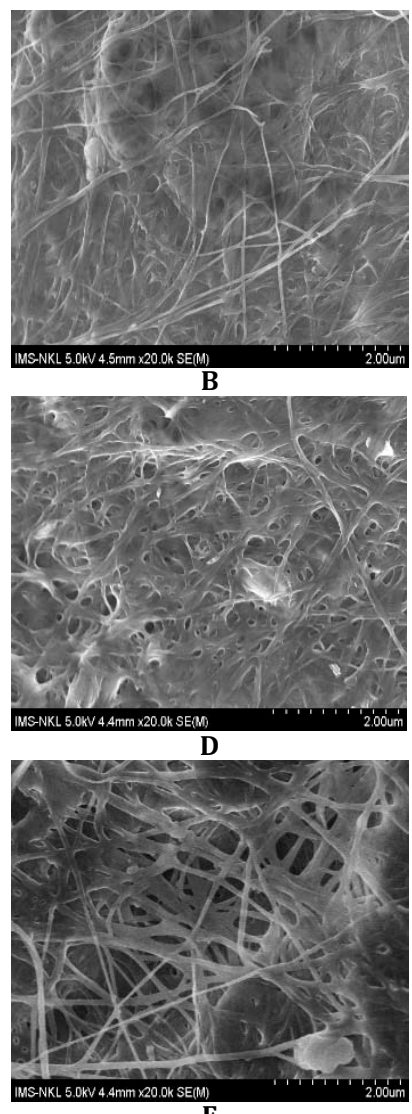

Fig. 2: The FE-SEM images of 3DNC-SM, 3DNC-CW and 3DNC-RW (A, C, E) and famotidine loaded 3DNC-SM, famotidine loaded 3DNC-CW and famotidine loaded 3DNC-RW (B, D, F)

\section{Evaluation of drug loading and entrapment efficiency of 3DNCs}

The experiment of the famotidine absorption into 3DNCs was performed in optimum conditions [14]. At the end of the experiment, the sample was removed from the absorbent solution to measure optical density (OD), based on the drug's calibration curve to calculate the amount of loaded famotidine and the famotidine entrapment efficiency of the 3DNCs. The results in table 1 have shown that there are no differences in the amount of loaded famotidine and famotidine entrapment efficacy of 3DNCs which were produced from different culture media.

\section{Determine the interaction of 3DNC to famotidine by FTIR}

The FTIR spectra of famotidine, 3DNC-SM, 3DNC-CW, 3DNCRW, famotidine loaded 3DNC-SM, famotidine loaded 3DNC-CW, and famotidine loaded 3DNC-RW are shown in fig. 3, 4, 5, 6, 7, 8 and 9.

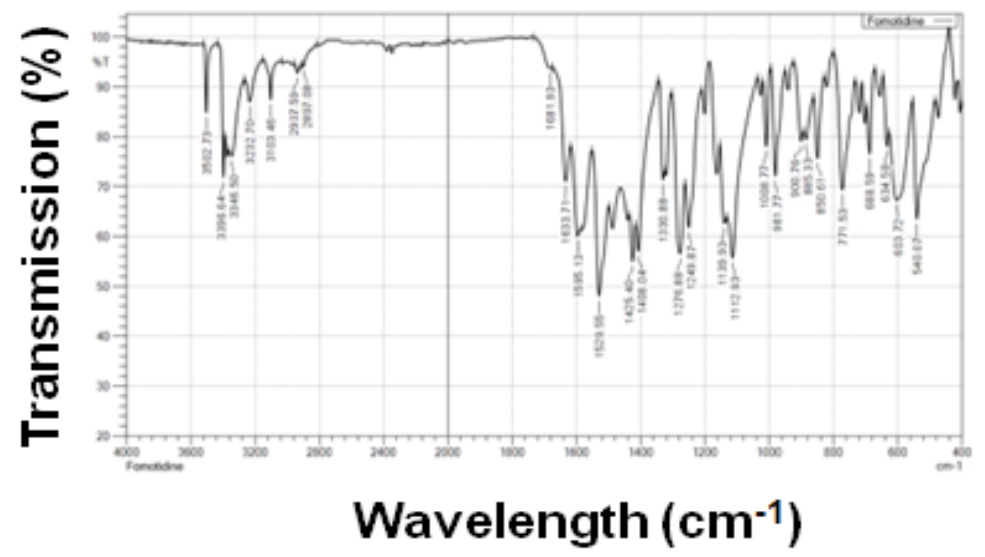

Fig. 3: FTIR spectra for famotidine 


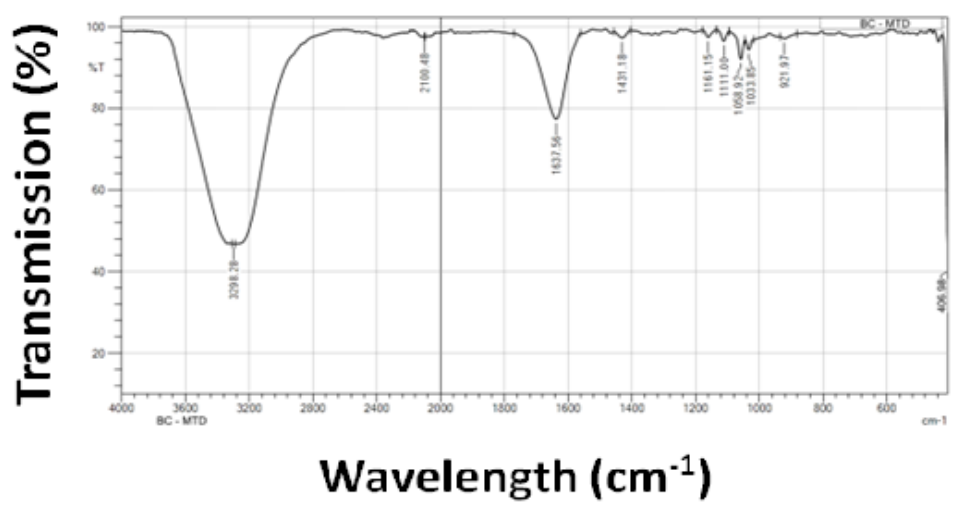

Fig. 4: FTIR spectra for 3DNC-SM

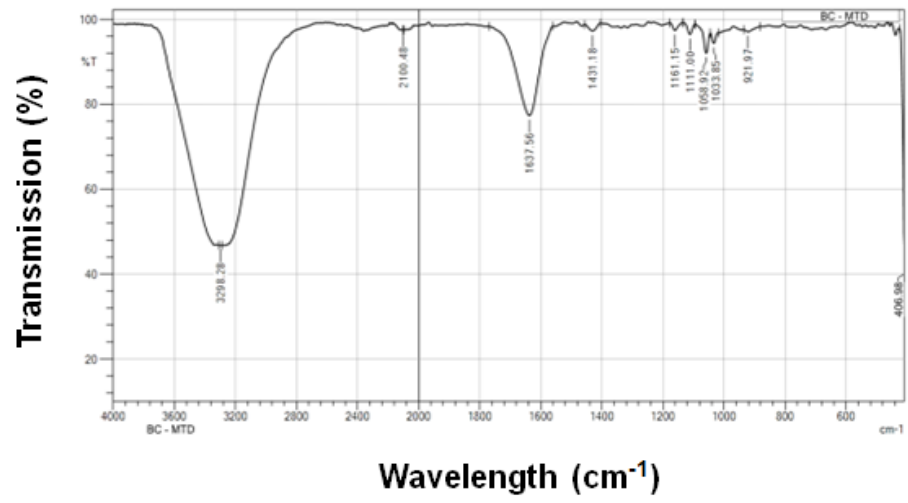

Fig. 5: FTIR spectra for 3DNC-CW

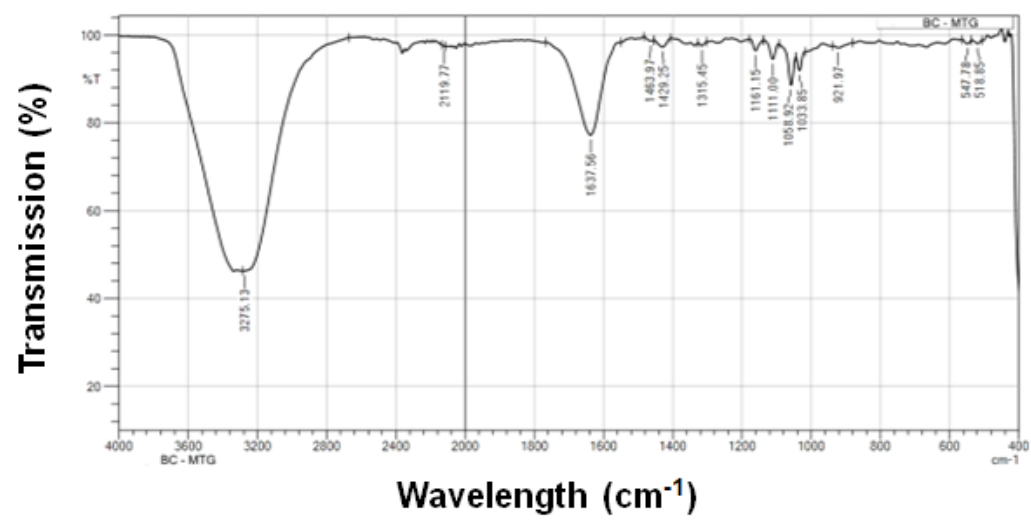

Fig. 6: FTIR spectra for 3DNC-RW

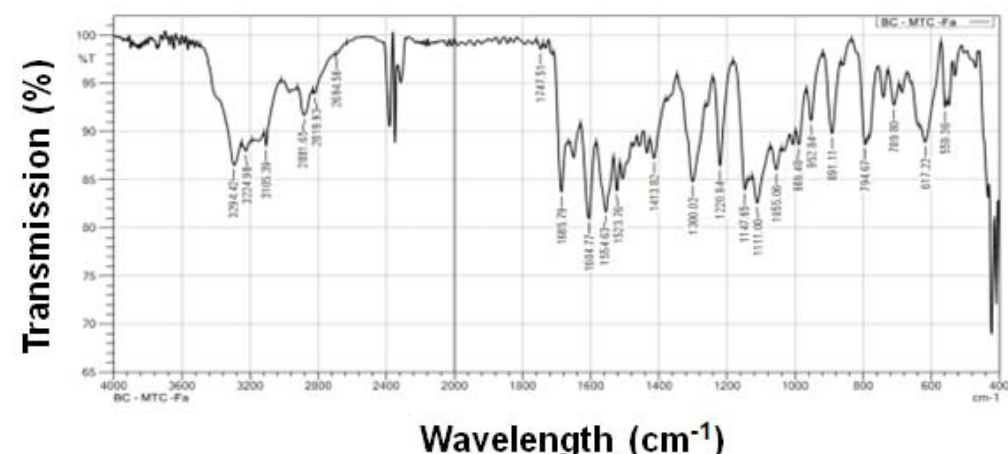

Fig. 7: FTIR spectra for famotidine loaded 3DNC-SM 
Table 1: Evaluation of famotidine loading and famotidine entrapment efficiency of 3DNCs (All values are expressed as mean \pm SD, $n=3$ )

\begin{tabular}{llll}
\hline 3DNC types & 3DNC-SM & 3DNC-CW & 3DNC-RW \\
\hline Loaded drug (mg) & $28.20 \pm 0.02$ & $28.27 \pm 0.08$ & $28.25 \pm 0.07$ \\
Efficiency (\%) & $90.00 \pm 0.03$ & $90.24 \pm 0.05$ & $90.84 \pm 0.09$ \\
\hline
\end{tabular}

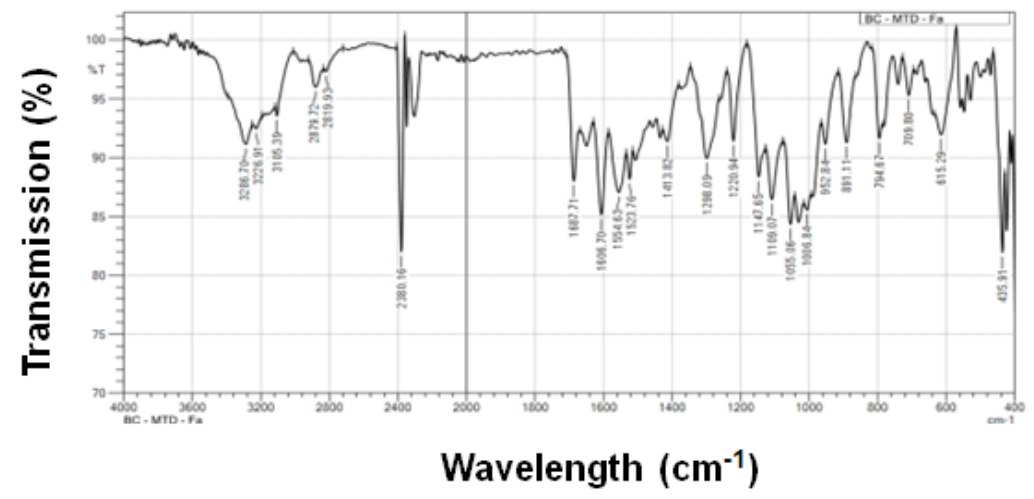

Fig. 8: FTIR spectra for famotidine loaded 3DNC-CW

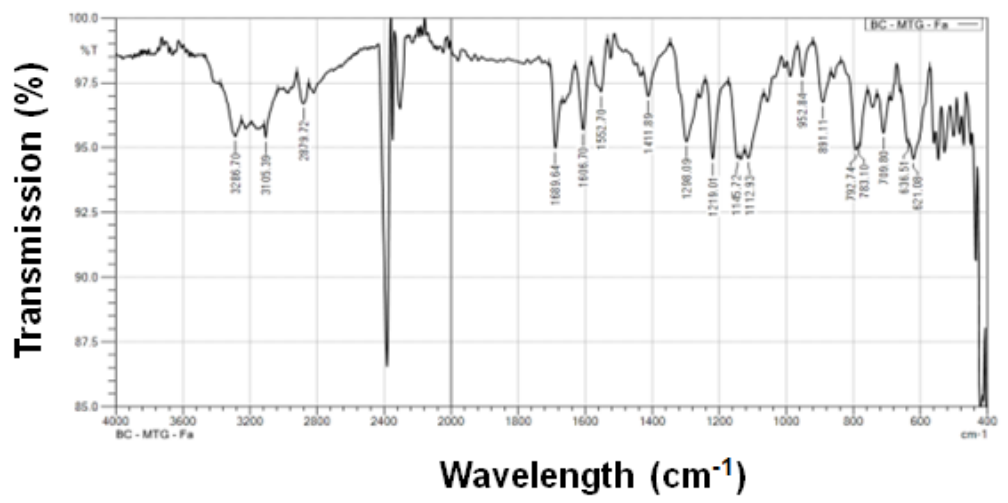

Fig. 9: FTIR spectra for famotidine loaded 3DNC-RW

The FTIR spectra of 3DNCs (3DNC-SM, 3DNC-CW, 3DNC-RW) in fig. 4-6 displayed the typical features of cellulosic substrates with intense bands around 3300, 2880, 1100 and $700 \mathrm{~cm}^{-1}$, associated with the vibrations of the- $\mathrm{OH}, \mathrm{C}-\mathrm{H}, \mathrm{C}-\mathrm{O}-\mathrm{C}$ and- $\mathrm{CH}_{2}$-groups, respectively $[2,11,20]$. FTIR spectra of the famotidine in fig. 3 showed that the famotidine exhibited various peaks due to the presence of specific functional groups. It is demonstrated that the peaks of the major functional groups of the famotidine were obtained at 1284, 1535, 3101 and 3394 [11].

The results of the FTIR spectra in fig. 3-9 showed that the same peaks of famotidine functional groups presented in the FTIR spectra of the famotidine loaded 3DNCs and other peaks of 3DNCs were present. It was observed that there were no changes in these main peaks in the FTIR spectra of a mixture of famotidine and 3DNCs (fig. 7-9). It is indicated that the IR spectrum for famotidine loaded 3DNCs showed characteristic bands at $3200-3500 \mathrm{~cm}^{-1}$, assigned to $\mathrm{CH}-\mathrm{OH}$ and $\mathrm{CH}_{2}-\mathrm{OH}$ in the 3DNCs and $\mathrm{NH}_{2}$ group in famotidine [11]. In the famotidine loaded 3DNCs, no additional peaks attributable to the formation of a complex appeared, but variations in the relative intensities of the characteristic peaks for 3DNCs and the famotidine could be observed. The FTIR study revealed no physical or chemical interactions of famotidine with 3DNCs as evidence from fig. 7-9. Consequently, the appearance of specific absorption peaks associated with functional groups of 3DNCs and famotidine revealed the successful famotidine loading into 3DNCs without any chemical alteration in the structure of the famotidine and 3DNCs. These results are very similar to those of our previous study $[2,8,11,20]$.

\section{DISCUSSION}

These results are consistent with other studies about the structure of 3DNC including nano-sized cellulose fibers that make up the three-dimensional structure network [2, 11, 20, 21]. It is demonstrated that SEM images of 3DNC-SM are generated from Gluconacetobacter xylinum after $24 \mathrm{~h}$ treatment of some conditions (double-distilled water, the artificial medium of the stomach and intestine, $\mathrm{NaOH}$ medium) showed that the porosity of the 3DNC cultured in SM in acidic and alkaline media increases when compared to neutral medium (double-distilled water). Therefore, it affirmed that have the contraction of cellulose fibers in these two conditions, and neutral medium does not affect the cellulose fibers [2]. Moreover, the results also showed that the 3DNCs with drugloaded and non-loaded have no apparent difference in results consistent with other studies $[2,11,20]$. For the 3DNC-SM or 3DNC$\mathrm{CW}$, the cellulose fibers have the stable structure without significant changes in structure when famotidine loaded under optimum condition. For the 3DNC-RW, the spatial structure of the cellulose fibers is noticeably altered after famotidine loading, the size of the holes in the famotidine loaded 3DNC-RWchanges, the cellulose fibers of 3DNC-RW are loosely linked; the structure of 3DNC-RW is unstable. In our previous study, 3DNC materials produced by Acetobacter xylinum in SM, CW, and RW were evaluated for some properties of pre-and post-curcumin loaded 3DNC materials. FESEM results also showed that the 3DNC produced from SM or CW consisted of stable cellulose fibers, with no significant change in the structure before and after loading of curcumin. FTIR spectra were determined without the formation of a covalent bond between 3DNC 
and curcumin and no change in the chemical composition of curcumin during 3DNC loading [20]. Compared to the 3DNC produced from the standard culture of pure bacteria strain (Gluconacetobacter xylinum) $[2,11,20]$, the 3DNC structure in the present study was not significantly different. It is concluded that the 3DNCs of the study have obtained by Acetobacter bacteria from fermented aqueous green tea extract in three types of culture media were effective in designing the famotidine delivery system.

\section{CONCLUSION}

This study has reported successful fabrication of 3DNCs by Acetobacter bacteria living in the fermented aqueous green tea extract from selected culture media and their characterization after absorbing with famotidine. 3DNC-CW and 3DNC-RW have the same characteristics as the 3DNC-SM, and 3DNCs can be fabricated with the desired thickness and diameter in selected culture media. The present study shows that 3DNCs absorbed the famotidine in optimum condition without the difference in famotidine loading $(28.2 \mathrm{mg}$ ) and famotidine entrapment efficiency (90\%). Moreover, surface morphologies of the samples studied by SEM have shown that the cellulose fibers of 3DNC-SM and 3DNC-CW have a stable structure without structural change when loading drug under optimum condition. The results indicate the potential for using 3DNC-SM and 3DNC-CW to design the drug delivery system.

\section{ACKNOWLEDGMENT}

The authors are thankful to the members of Biomedical and Pharmaceutical Engineering Research Group (BIPERG) at Institute of Scientific Research and Applications (ISA)-Hanoi Pedagogical University 2 (HPU2) and collaborative members who have helped to do some of the work of this research. The authors would like to thank the Institute of Scientific Research and Applications (HPU2) for providing necessary facilities and support.

\section{AUTHORS CONTRIBUTIONS}

First author conceived the idea. All the authors have carried out the research work under the supervision of first author. First author drafted the manuscript.

\section{CONFLICT OF INTRESTS}

The authors declare no conflicts of interest.

\section{REFERENCES}

1. Amin MCIM, Abadi A, Ahmad N, Katas H, Jamal JA. Bacterial cellulose film coating as drug delivery system: physicochemical, thermal and drug release properties. Sains Malays 2012;41:561-8.

2. Huang L, Chen X, Nguyen TX, Tang H, Zhang L, Yang G. Nanocellulose 3D-networks as controlled-release drug carriers. J Mater Chem B 2013;1:2976-84.

3. Zhu X, Zhang Z, Qi X, Xing J. Preparation of multiple-unit floating-bioadhesive cooperative minitablets for improving the oral bioavailability of famotidine in rats. Drug Delivery 2014;21:459-66.

4. Nguyen TX, Huang L, Liu L, Abdalla AME, Gauthier M, Yang G. Chitosan-coated nano-liposomes for the oral delivery of berberine hydrochloride. J Mater Chem B 2014;2:7149-59.
5. Surendran V, Singh A, Sampathkumar KP. Synthesis and characterization of novel amino acid prodrug of famotidine. Int J Pharm Pharm Sci 2015;7:403-8.

6. Malladi M, Jukanti R. Floating pulsatile drug delivery system of famotidine: Design, statistical optimization, and in vitro evaluation. Int J Pharm Pharm Sci 2016;8:169-81.

7. Ain S, Kumar B, Pathak K. Development and characterization of controlled release famotidine matrix tablets containing complexes. Int J Appl Pharm 2017;9:38-46.

8. Kumar R, Gautam PK, Chandra A. Formulation and evaluation of famotidine micro balloons with enhanced anti-ulcer activity. Int J Appl Pharm 2018;10:131-40.

9. Singhai NJ, Maurya R, Ramteke S, Jain SK. Formulation and evaluation of amoxicillin-trihydrate, metronidazole and famotidine loaded-mucoadhesive gastro-retentive films. Int J Appl Pharm 2019;11:131-42.

10. Greenwalt CJ, Steinkraus KH, Ledford RA. Kombucha, the fermented tea: microbiology, composition, and claimed health effects. J Food Prot 2000;63:976-81.

11. Nguyen TX. Isolation of Acetobacter xylinum from kombucha and application of cellulose material produced by bacteria from some culture media for drug carrier. Int J Sci Res 2019;8:10449.

12. Hestrin S, Schramm M. Synthesis of cellulose by Acetobacter xylinum, 2. Preparation of freeze-dried cells capable of polymerizing glucose to cellulose. Biochem J 1954;58:345-52.

13. Nguyen CDT, Ho LYT, Nguyen TV. Study on the culture of Acetobacter xylinum for preparation of bio-membrane used for treatment of burn and skin trauma. HCM City J Med 2002;6:139-41.

14. Phan VHT, Bui TM, Phung HKT, Nguyen TX, Trieu TN. Optimization of famotidine loaded efficiency for bacterial cellulose material fermented from green tea by response surface methodology and box-behnken model. Vietnam Pharm J 2018;501:3-6.

15. Nguyen HT, Pham HT. Selection of Acetobacter xylinum suitable for use in large scale bacterial cellulose production. Vietnam J Genet Appl 2003;3:49-54.

16. Huynh LNT, Nguyen TV. Study on characteristics of bacterial cellulose from Acetobacter xylinum used as burnishing membrane. Vietnam Pharm J 2006;361:18-20.

17. Dinh NKT, Nguyen VTT, Tran QN. Research on Acetobacter xylinum producing bacterial cellulose for therapeutic purpose of burn wound treatment. Vietnam J Sci Technol 2012;50:453-62.

18. Ricardo JBP, Paula AAPM, Carlos PN, Tito T, Sara D, Patrizia S. Antibacterial activity of nanocomposites of silver and bacterial or vegetable cellulosic fibers. Acta Biomater 2009;5:2279-89.

19. Kuswandi B, Jayus, Larasati TS, Abdullah A, Heng LY. Real-time monitoring of shrimp spoilage using on-package sticker sensor based on natural dye of curcumin. Food Anal Methods 2012;5:881-9.

20. Nguyen TX. Study of some properties of curcumin loaded 3Dnano-cellulose networks produced by Acetobacter xylinum. TNU J Sci Technol 2018;184:83-8.

21. Nguyen TX. Evaluation of the in vivo bioavailability of famotidine loaded 3D-nano-cellulose networks produced by Acetobacter xylinum in some culture media. VNU J Sci 2018;34:1-7. 